\title{
Appraisal of Anchor Arrangement and Size On Sand-Geogrid Interaction In Direct Shear
}

Mahmood Reza Abdi ( $\nabla$ abdi@kntu.ac.ir)

K.N. Toosi University of Technology https://orcid.org/0000-0002-3473-9677

Mehdi PourRamezan Chafjiri

K.N. Toosi University of Technology

\section{Research Article}

Keywords: reinforced, anchor, geogrid, direct shear, interaction

Posted Date: November 30th, 2021

DOI: https://doi.org/10.21203/rs.3.rs-1104294/v1

License: @ (i) This work is licensed under a Creative Commons Attribution 4.0 International License. Read Full License 


\section{Abstract}

Soil - reinforcement interaction is a major factor in the analysis and design of reinforced earth structures. In current research the effects of attaching elements of different size and numbers as anchors on enhancement of interaction at soil - geogrid interface under direct shear conditions were studied. Poorly and well graded sands $\left(\mathrm{S}_{\mathrm{C}} \& \mathrm{~S}_{\mathrm{f}}\right)$, a high density polyethylene geogrid, anchors with three different size and numbers (layouts) and clamping length of $2 \mathrm{~cm}$ from shear surface were used. Samples were prepared dry at a relative density of $80 \%$ in a $30 \times 30 \mathrm{~cm}$ direct shear box and subjected to normal pressures of 12.5, 25 and 50kPa with the shear load applied at a rate of $1 \mathrm{~mm} / \mathrm{min}$. Results of the assessment show that anchored geogrids improve shear resistance at interface mainly due to mobilization of passive soil resistance that is significantly influenced by the magnitude of the normal pressure and the number and size of anchors. Interaction enhancements achieved varied between a minimum of $8 \%$ and a maximum of $42 \%$.

\section{Introduction}

Soil reinforcement employing geosynthetics has become an engineering solution for solving problems associated with soil structures such as retaining walls and embankments. It is an environmentally friendly and economically viable method without the need for skilled workers or specialized equipment that can be executed in all weather conditions. Jewell et al., 1984; Lee and Manjunath, 2000; Anas et al., 2016; Abdi and Mirzaeifar, 2017 have stated that for safe and economic design of reinforced soil structures knowledge of interaction at interface is crucial which is significantly influenced by reinforcement type and characteristics, soil properties, boundary and loading conditions, etc. Soil - geosynthetic interaction is usually considered under pull out or direct shear mode and the effects of influential factors such as soil density and type, particle shape and size, moisture content, geosynthetic tensile strength and geometry have been explored by Lopes \& Ladeira, 1996; Athanasopoulos, 2002; Varuso et al., 2005; Latha \& Murthy, 2006; Liu et al., 2009; Dash, 2010; Lopes \& Silvano, 2010; Abdi \& Arjomand, 2011; Tuna \& Altun, 2012; Abdi \& Zandieh, 2014; Chen et al., 2014; Ferreira et al., 2015; Thuo et al., 2015; Ferreira et al., 2016; Prashanth et al., 2016; Infante et al., 2016; Wang et al., 2016; Abdi \& Mirzaeifar, 2017; Balakrishnan \& Viswanadham, 2017. Xu et al. 2020, using experimental and numerical methods investigated the reinforcing mechanism of geosynthetic - reinforced granular soils under plane strain conditions. Wang et al., 2020 studied the creep behavior of sand - geogrid under different loading levels and reported that creep mainly occurs near the pullout point and deformations is reduced from tensile end to the fixed end of the geogrid. Effect of backfill compaction density on reinforced soil walls has been investigated using Centrifuge by Xu et al., 2020. Results showed that displacement of the model with inadequate compaction $\left(D_{r}=65 \%\right)$ was $30 \%$ greater than the model with $\mathrm{Dr}=95 \%$.

Land shortages and increased prices along with regulatory constraints, have necessitated the need for steeper and higher reinforced soil structures, cost of which mainly depend on the volume of earthworks and the amount of reinforcement required that are influenced by soil-reinforcement interactions. Because enhancing interactions has attractions from economical and constructional perspective which are crucial factors in the design of reinforced earth structures many researchers including Chenggang, 2004; Liu et al., 2014; Kargar \& Mir Mohammad Hosseini, 2016; Moghaddas Tafreshi et al., 2016; Tavakoli Mehrjardi \& Amjadi Sardehaei, 2017, Abdi and Safdari Seh Gonbad, 2018 have investigated different methods of improving interactions. Soilgeogrid interactions are due to friction at interfaces, soil-soil shear strength within apertures and passive resistance in front of transverse ribs. Goodhue et al. ,2001; Lopez, 2002; Palmeira, 2004; Abdi et al., 2009 and Xu et al., 2018 have shown that in direct shear mode the first two and under pull out condition the third mechanism is the main contributor to stability. As under direct shear mode, reinforcement tensile strength and passive resistance do not contribute significantly to stability of reinforced earth structures, this necessitates longer embedment lengths and larger volumes of soil, leading to greater costs. Thus, to alleviate this problem researchers have attempted to improve soil - geosynthetic interaction by different methods some of which are schematically shown in Table 1.

In current study and to complete the research conducted by Abdi and Safdari Seh Gonbad (2018), the effects of soil grading, attached element size and arrangements together with normal pressures on interactions in direct shear mode have been assessed. Poorly and well graded sands, a geogrid type, three different element sizes, arrangements and normal pressures were adopted for the investigation.

\section{Experimental Procedure}

\subsection{Test method}

Large scale direct shear tests $30 \times 30 \times 17 \mathrm{~cm}$ were conducted on unreinforced, reinforced and anchored reinforced samples to determine the sands shear strength characteristics and the interaction parameters at soil - geogrid interface according to ASTM D3080-04 and ASTM D5321-08 respectively. Horizontal and vertical displacements were measured using LVDTs and a load cell was used for measuring shear forces together with an automatic data acquisition system.

\subsection{Materials}

\subsubsection{Soils}

Fine uniform and coarse non-uniform sands referred to from here after in the text and the figures by symbols $\mathrm{S}_{\mathrm{f}}$ and $\mathrm{S}_{\mathrm{c}}$ for abbreviation were used as soils (see Fig. 1). Sieve analysis was conducted on representative samples with the summary of the physical and the mechanical characteristics given in Table 2. According to the Unified Soil Classification System (USCS), the fine uniform sand $\left(S_{f}\right)$ was classified as SP (poorly graded sand) and the coarse nonuniform sand $\left(\mathrm{S}_{\mathrm{c}}\right)$ as SW (well graded sand).

\subsubsection{Geogrid}


Figure 2 shows the high density polyethylene (HDPE) geogrid marketed as CE131 product of Meshiran representative of Netlon, UK used as the reinforcement together with its characteristics presented in Table 3.

\subsubsection{Anchors}

Figure 3 shows the plastic rosary beads of 3 different sizes and shape labelled $A_{1}, A_{2}$ and $A_{3}$ and called anchors hereafter with their specifications presented in Table 4. These plastic elements were adopted because they already had holes through which wires for their attachment to geogrid surface could be passed.

As under direct shear conditions, failure manifests as soil slippage on upper geogrid surface (Hsieh et al., 2011), consequently anchors were only attached to this surface. Based on the results of Abdi and Safdari, 2018, for maximum interaction anchors were attached to the upper geogrid surface using wires $2 \mathrm{~cm}$ in length at approximately $45^{\circ}$ to the horizontal. Figure 4 shows the arrangements investigated according to which 6,10 and 20 anchors were attached to each $30 \times 30 \mathrm{~cm}$ geogrid specimen. The coding used for referring to the samples in the text, figures and the tables is $\mathrm{SiAj}_{\mathrm{k}}$, meaning "sand, $\mathrm{S}_{\mathrm{i}}$; anchor, $A_{j}$ and arrangement $L_{k} "$.

\subsection{Sample preparation method}

To prepare samples, initially soils were placed on trays and completely dried under laboratory conditions. By adopting relative density of $80 \%$, dry weight of soil required for filling the lower and the upper halves of the shear box in two layers were determined. After placing each soil layer in the lower and the upper halves of the shear box they were compacted using a $10 \times 10 \mathrm{~cm}$ metal rammer. The number of plastic hammer blows necessary for reaching the required relative density was predetermined by trial and error during preliminary experiments. To avoid friction influencing the results the upper and the lower shear box contact surfaces were lubricated.

In case of soil-geogrid and soil-anchored geogrid samples, to prevent displacement of the reinforcement during testing, it was initially positioned in the lower half of the shear box as shown in Fig. 5, and then sand was placed in two layers and each layer compacted. Subsequently the geogrid was laid back on the soil surface at the interface of the lower and the upper shear boxes before the upper half of the shear box was positioned, filled with soil layers and compacted. Subsequently the loading plate was placed on the soil surface in the upper shear box, LVDTs positioned, appropriate normal pressure applied and the shear load set at a rate of $1 \mathrm{~mm} / \mathrm{min}$.

As direct shear failure usually manifests in the upper parts of reinforced earth structures where vertical pressures are relatively low (Palmeira, 2009), thus, normal pressures of $12.5,25$ and $50 \mathrm{kPa}$ equivalent to 0.6 to $2.5 \mathrm{~m}$ height of soil were adopted. Tests were displacement controlled and loading continued up to a maximum horizontal displacement of $15 \mathrm{~mm}$ (i.e. $5 \%$ strain). At the end of each test, geogrids were exhumed and inspected for integrity and anchor detachment. In no case geogrid was damaged and in only a few cases some anchors had been detached and needed replacement.

\section{Enhanced Interaction Coefficient}

Various researchers have defined the ratio of "reinforced soil shear strength to unreinforced soil shear strength" as interaction coefficient ( $\left.\mathrm{C}_{\mathrm{i}}\right)$ which is used as a criterion for evaluating soil - geosynthetic interaction )Tatlisoz et al., 1998; Abdi \& Arjomand, 2011(. In current research, "enhanced coefficient of interaction $\left(\mathrm{C}_{\mathrm{ie}}\right)$ has been introduced which is defined as the ratio of "soil - anchored geogrid shear strength to soil - geogrid shear strength". This coefficient denotes improvement in soil - geogrid interaction due to the attachment of various numbers of anchors as follows:

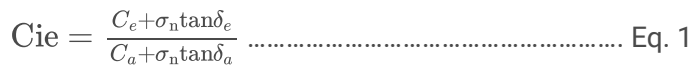

Where: $\delta_{\mathrm{e}}=$ soil - anchored geogrid interaction angle $\left(^{\circ}\right)$

$\delta_{\mathrm{a}}=$ soil - geogrid interaction angle $\left(^{\circ}\right)$

$\mathrm{C}_{\mathrm{e}}=$ apparent adhesion at soil - anchored geogrid interface $\left(\mathrm{kN} / \mathrm{m}^{2}\right)$

$C_{a}=$ apparent adhesion at soil - geogrid interface $\left(\mathrm{kN} / \mathrm{m}^{2}\right)$

$\sigma_{\mathrm{n}}=$ applied normal pressure $\left(\mathrm{kN} / \mathrm{m}^{2}\right)$

As cohesion less soils were investigated, the above equation simplifies to:

$\mathrm{C}_{\mathrm{ie}}=\frac{\tan \delta_{\mathrm{e}}}{\tan \delta_{\mathrm{a}}}$ Eq. 2

\section{Results And Discussion}

Large scale direct shear tests were conducted on unreinforced, reinforced and anchor - reinforced samples, results of which are presented below as variations of shear stress - shear displacement and shear strength envelopes.

\subsection{Unreinforced samples}


Result of tests carried out on samples of unreinforced sands $S_{c}$ and $S_{f}$ are shown respectively in Figs. 6 and 7 , and were used as a criterion for evaluating interaction enhancements. It is observed for both sets of samples that shear stresses initially increase with shear displacement (i.e. hardening behaviour) and after reaching failure state (i.e. maximum value) reduce with further displacement displaying softening behaviour which is typical of granular materials. The rate of change of shear stress with shear displacement for all samples are relatively the same up to $5 \mathrm{~mm}$ displacement and the main differences are in the maximum shear stress values and the corresponding shear displacements. Samples of sand $\mathrm{S}_{\mathrm{c}}$ with non-uniform and coarser-grains consistently displayed higher shear stress values compared to $S_{f}$ samples subjected to the same normal pressures. Sand $S_{f}$ samples reach their maximum and ultimate states respectively at shear displacements of approximately 5 to $12 \mathrm{~mm}$ whereas $\mathrm{S}_{\mathrm{C}}$ samples reach their maximum strength at 10 mm shear displacement and do not reach ultimate state by the end of the tests (i.e. $15 \mathrm{~mm}$ displacement). Internal angles of friction of $S_{c}$ and $S_{f}$ sands were determined respectively as 44.8 and 33.8 degrees, with negligible apparent cohesions (Fig. 8).

\subsection{Reinforced Samples $\left(S_{c} G \& S_{f} G\right)$}

Figures 9 to 11 show variations of shear stress - shear displacement and failure envelopes obtained for reinforced $S_{c} G$ and $S_{f} G$ samples respectively. Considering Figs. 9 and 10, it can be seen that by reinforcing sands $S_{c}$ and $S_{f}$ samples, trend of variations of shear stresses with shear displacement are similar to behaviour observed for unreinforced samples with slightly smaller maximum shear stresses, particularly at $\sigma_{\mathrm{n}}=50 \mathrm{kPa}$. Samples show initial hardening and subsequent softening behaviour after failure supporting observations of Liu et al. (2009) and Mossallahnezhad et al. (2016). The reduction in shear strengths is a clear indication of poor soil - geogrid interaction under direct shear mode. These changes are attributed to soil particle slippage on upper geogrid surfaces without its tensile strength and soil passive resistance being mobilised as well as the reduction of soil - soil interfaces also reported by Cazzuffi et al., (1993); Alfaro et al., (1995), Abu-Farsakh et al., (2007); Liu et al., (2009) and Kim and Ha (2014).

Failure envelopes for the reinforced as well as the unreinforced samples for comparative purposes are presented together on Fig. 11. Interaction angles measured for the reinforced $S_{c}$ and $S_{f}$ samples were respectively 39.2 and $28.3^{\circ}$ showing 13 and $16.3 \%$ reduction compared to the unreinforced samples. Smaller reduction in angle of interaction of reinforced $S_{c}$ compared to $S_{f}$ samples is attributed to its non-uniform, larger and angular particles which interacted more effectively with each other and the geogrid members. Apparent adhesions for reinforced samples were negligible and disregarded in accord with the results reported by Goodhue et al. (2001) and Atanasopolus (2002). They attributed the small apparent adhesions to soil suction at particle contacts as well as friction intrinsically built in the direct shear equipment.

\subsection{Anchor-reinforced samples $\left(S_{c} A_{j} L_{k} \& S_{f} A_{j} L_{k}\right)$}

To improve soil - geogrid interaction at interface in direct shear condition and compensate for the loss of shear strengths as a result of reinforcing, elements with three different sizes and arrangements (i.e. layouts) having an anchorage length of $2 \mathrm{~cm}$ were attached to the upper geogrid surface and tested. Because of the variety of samples only the results for $S_{c} A_{1} L_{1}$ and $S_{f} A_{1} L_{1}$ samples that resulted in the greatest improvements are shown on Figs. 12 to 15. For comparative purposes results of reinforced samples are also included.

Considering Figs. 12 and 14 it can be observed that for both sets of samples subjected to low normal pressure of $12.5 \mathrm{kPa}$, attachment of anchors to geogrids has not resulted in noticeable improvement in shear stresses at interface in comparison to equivalent reinforced samples. By increasing normal pressures to 25 and particularly $50 \mathrm{kPa}$, attachment of elements to the geogrids has resulted in significant improvement in maximum shear stresses and reduction of corresponding shear displacements. In both sets of samples subjected to $\sigma_{n}=50 \mathrm{kPa}$ the rate of change in shear stresses with shear displacement have significantly increased compared with samples subjected to $\sigma_{n}=12.5 \mathrm{kPa}$, clearly indicating that soil - anchored geogrid interaction are dependent on the magnitude of the normal pressures. The improvements are credited to greater particle confinement, increased soil - geogrid, soil - anchor and soil - soil interactions as well as passive resistance mobilization in front of the anchors.

At the early stages of loading ( $<2 \mathrm{~mm}$ shear displacement), shear stresses for reinforced and anchor reinforced samples particularly those subjected to $\sigma_{\mathrm{n}}$ $=12.5$ and $25 \mathrm{kPa}$ are very similar and the curves almost overlap. As loading continues the rate of change of shear stresses with shear displacements gradually decrease. After reaching maximum values (i.e. failure state) shear stresses gently decrease and samples reach ultimate states at shear displacements of 5 to $10 \mathrm{~mm}$ depending on the normal pressure. Generally the higher the normal pressure, the greater the maximum shear displacement at which ultimate state is reached. Anchor reinforced samples reach failure states at smaller shear displacements than equivalent reinforced samples and mobilise shear strength at a faster rate particularly those samples subjected to $\sigma_{n}=50 \mathrm{kPa}$. As an example, by anchoring $S_{c} G$ sample (i.e. $\left.S_{c} A_{1} L_{1}\right)$ subjected to $\sigma_{n}=50 \mathrm{kPa}$ maximum shear stresses increased from 44.51 to $63.23 \mathrm{kPa}$, which is an improvement of 42 percent (Fig. 12). Enhancements in soil-geogrid interaction by the addition of metallic angles to the reinforcement in pull out tests have also been reported by Sadat Taghavi and Mosallanejad (2016) and Mosallanejad et al., (2017).

\subsection{Failure envelopes}

Summary of all test results as maximum shear strengths $\left(\tau_{\max }\right)$, interaction coefficients $\left(\mathrm{C}_{\mathrm{i}}\right)$, enhanced interaction coefficients $\left(\mathrm{C}_{\mathrm{ie}}\right)$, internal friction angles $(\Phi)$, interaction angles at soil - geogrid interface $\left(\delta_{\mathrm{a}}\right)$ together with soil - anchored geogrid interaction angle $\left(\delta_{\mathrm{e}}\right)$ are presented in Table 5 .

\subsubsection{Unreinforced and Reinforced samples}

Considering Table 5, it can be seen that angles of internal friction determined for the unreinforced $\mathrm{S}_{\mathrm{C}}$ and $\mathrm{S}_{\mathrm{f}}$ samples were $44.8^{\circ}$ and $33.8^{\circ}$ which were reduced to $33.8^{\circ}$ and $28.3^{\circ}$ respectively as a result of reinforcing with geogrid (i.e. $S_{c} G \& S_{f} G$ ) giving interaction coefficients of 0.88 and 0.87 respectively. 
The reduction in interactions is attributed to slippage of soil particles on upper surfaces of geogrid elements, inadequate passive soil resistance and reduction of overall soil - soil particle interfaces.

\subsubsection{Anchored geogrid samples}

Summary of the results presented in Table 5, clearly show that reinforcing sands with geogrid under direct shear mode reduces interactions and the attachment of elements to the reinforcement surfaces significantly improves interaction at interface. Attachment of different sizes and arrangement of anchors to geogrid surfaces in both sets of samples not only compensated the reduction in shear strengths, in fact in most cases soil - geogrid interaction angles were enhanced to values greater than sands friction angles. Highest $C_{i e}$ values of 1.42 and 1.35 showing respectively 42 and $35 \%$ improvement in interactions were achieved for $S_{c} A_{1} L_{1}$ and $S_{f} A_{1} L_{1}$ samples. For the same arrangement of anchors $\left(L_{1}, L_{2}\right.$ or $\left.L_{3}\right)$, the larger elements with greater base and surface areas (i.e. $A_{1}>A_{2}>A_{3}$ ) consistently produced the highest enhancements which signifies the importance of passive resistance mobilization on interactions. It is observed that for the coarser non-uniform sand $\left(S_{c}\right)$ the attachment of even 6 of the smallest elements (i.e. $\left.S_{c} A_{3} L_{3}\right)$ has almost compensated the reduction in soil shear strength due to reinforcing under direct shear mode whereas for the finer uniform sand $\left(\mathrm{S}_{\mathrm{f}}\right)$ at least 10 of the same elements are required (i.e. $\mathrm{S}_{\mathrm{f}} \mathrm{A}_{3} \mathrm{~L}_{2}$ ). This behaviour clearly emphasises the important rule of particle grain size and distribution on soil - geogrid interaction.

According to the results enhanced coefficients of interactions $\left(\mathrm{C}_{\mathrm{ie}}\right)$ obtained for both $\mathrm{S}_{\mathrm{c}}$ and $\mathrm{S}_{\mathrm{f}}$ sands subjected to normal pressures of 12.5 and $25 \mathrm{kPa}$ do not differ significantly and are almost the same as interaction coefficients $\left(\mathrm{C}_{\mathrm{i}}\right)$. This means that attachment of elements to geogrid reinforced samples subjected to low normal pressures do not lead to significant improvements in soil - geogrid interactions. By increasing the normal pressure to $50 \mathrm{kPa}$, enhanced coefficients of interaction show significant changes and vary between a minimum of 1.16 for $S_{C} A_{3} L_{3}$ and a maximum of 1.42 for $S_{c} A_{1} L_{1}$ respectively and 1.08 and 1.35 for $S_{f} A_{3} L_{3}$ and $S_{f} A_{1} L_{1}$ samples. These represent enhancements of 16 to $42 \%$ for $S_{c}$ with $D_{50}=1 \mathrm{~mm}$ and 8 to $35 \%$ for $S_{f}$ samples with $D_{50}=0.22 \mathrm{~mm}$. Thus it is concluded that normal pressure is a more influential factor on enhancing soil - geogrid interaction than particle size and distribution.

Figures 16 and 17 clearly show that for a particular sand (i.e. $S_{c}$ or $S_{f}$ ) and element layout (i.e. $L_{1}, L_{2} \& L_{3}$ ) the highest improvements in interaction have consistently been achieved for the samples with the largest anchors (i.e. $A_{1}$ ). Results also show that attachment of even 6 anchors to the geogrids (i.e. $L_{3}=$ 6) improved anchored interaction friction angles (i.e. $\delta_{e}$ ) to those of soil internal friction angles. These observations indicate that the larger the size and the number of attached elements to the geogrid surface, the greater the mobilization of passive soil resistance in front of these elements and thus the higher and the more effective the soil-geogrid interaction.

\section{Conclusions}

Reinforcing soils under direct shear mode result in the reduction in shear strength due to poor soil - geogrid interaction. In present research, improvement of soil - geogrid interaction by mobilizing passive soil resistance using elements as anchors was investigated. Effects of influential factors such as anchor size and layout (numbers), soil particle size and distribution together with normal pressure on interaction were assessed and the following conclusions drawn:

- Reinforcing coarse grained non-uniform $\left(\mathrm{S}_{\mathrm{c}}\right)$ and fine grained uniform $\left(\mathrm{S}_{\mathrm{f}}\right)$ sands with geogrid under direct shear mode results in the reduction of soil geogrid interaction characteristics at interface and thus overall shear strength.

- Attachment of elements as anchors to geogrid surface significantly enhances shear strength characteristics at soil - geogrid interface in case of both coarse grained non-uniform $\left(\mathrm{S}_{\mathrm{c}}\right)$ and fine grained uniform $\left(\mathrm{S}_{\mathrm{f}}\right)$ sands shown by higher interaction angles $\left(\delta_{\mathrm{e}}\right)$ achieved compared with soil internal friction angles $(\varphi)$.

- Interaction enhancements are influenced by anchor size and numbers (i.e. layouts) as well as magnitude of normal pressure. Anchors with the larger cross section and greater numbers result in greater soil - anchor interaction and mobilization of passive soil resistance.

- Normal pressure due to the confinement effects it provides is shown to be a more influential factor on enhancing soil-geogrid interaction than soil particle size and gradation.

- Attaching anchors to geogrids resulted in improving interaction angles in $\mathrm{S}_{\mathrm{c}}$ samples by a minimum and a maximum of 4.5 and 10.9 degrees (i.e. 10 to $24.3 \%$ ) and in $S_{f}$ samples by 2.1 and 9.7 degrees (i.e. 6.2 to $28.8 \%$ ) in comparison to unanchored reinforced samples. Minimum enhancements correspond to samples with the lowest number and the smallest anchors (i.e. $L_{3} \& A_{3}$ ) and the maximum to samples with the largest number and the largest anchors (i.e. $L_{1} \& A_{1}$ ).

\section{References}

1. Abdi, M. R., Sadrnejad, A., \& Arjomand, M. A. (2009). Strength enhancement of clay by encapsulating geogrids in thin layers of sand. Geotextiles and Geomembranes, 27(6), 447-455. https://doi.org/10.1016/j.geotexmem. 2009.06.001

2. Abdi, M. R. \& Arjomand, M. A. (2011). Pull out tests conducted on clay reinforced with geogrid encapsulated in thin layers of sand. Geotextiles and Geomembranes, 29(6), 588-595.

3. Abdi, M. R. \& Zandieh, A. R. (2014). Experimental and numerical analysis of large scale pull out tests conducted on clays reinforced with geogrids encapsulated with coarse material. Geotextiles and Geomembranes, 42(5), 494-504. 
4. Abdi, M. R. \& Mirzaeifar, H. (2017). Experimental and PIV evaluation of grain size and distribution on soil - geogrid interaction in pull out test, Soils and Foundations 57 (2017), 1046-1059.

5. Abdi, M. R., \& Safdari Seh Gonbad, M. (2018). Enhancement of soil-geogrid interaction in direct shear mode using attached elements as anchors. European Journal of Environmental and Civil Engineering, 1-19. https://doi.org/10.1080/19648189.2018.1454861

6. Abdi, M. R., \& Safdari Seh Gonbad, M. (2019). Studying the effect of roughness on soil-geotextile interaction in direct shear test. Journal of Engineering Geology, 12(5), 1-30.

7. Abu-Farsakh, M., Coronel, J., \& Tao, M. (2007). Effect of soil moisture content and dry density on cohesive soil-geosynthetic interactions using large direct shear tests. Journal of Materials in Civil Engineering, 19(7), 540-549.

8. Alfaro, M. C., Miura, N. \& Bergado, D. T. (1995). Soil-geogrid reinforcement interaction by pullout and direct shear tests. Geotechnical Testing Journal, 18(2), 157-167.

9. Anas, I., Farouk, A., El Sideek, M. B., Hassan, A. R., \& Mowafy, Y. (2016). An Innovative Shape of Geogrid to increase Pull-Out Capacity. IOSR Journal of Mechanical and Civil Engineering, 13(4), 72-79.

10. ASTM D2487. (2011). Standard practice for classification of soils for engineering purposes (unified soil classification system). West Conshohocken, PA: ASTM International. https://doi.org/10.1520/D2487-11

11. ASTM D3080. (2004) Standard test method for direct shear test of soils under consolidated drained conditions. West Conshohocken, PA: ASTM International.

12. ASTM D4253. (2016). Standard test methods for maximum index density and unit weight of soils using a vibratory table. West Conshohocken, PA: ASTM International.

13. ASTM D4254. (2016). Standard test methods for minimum index unit weight of soils and calculation of relative density. West Conshohocken, PA: ASTM International.

14. ASTM D422. (2007). Standard test method for particle-size analysis of soils. West Conshohocken, PA: ASTM International.

15. Athanasopoulos, G. A. (2002). Effect of particle size on the mechanical behaviour of sand-geotextile composites. Geotextiles and Geomembranes, 12(3), 255-273.

16. Balakrishnan, S. \& Viswanadham, B. V. S. (2017). Evaluation of tensile load-strain characteristics of geogrids through in-soil tensile tests. Geotextiles and Geomembranes, 45(1), 35-44.

17. Cazzuffi, D., Picarelli, L., Ricciuti, A. \& Rimoldi, P. (1993). Laboratory investigations on the shear strength of geogrid reinforced soils. In Geosynthetic Soil Reinforcement Testing Procedures, ASTM Spec. Tech. Publ. 1190, 119-137.

18. Chen, C., McDowell, G. R. \& Thom, N. H. (2014). Investigating geogrid-reinforced ballast: Experimental pull-out tests and discrete element modelling. Soils and Foundations, 54(1), 1-11.

19. Chenggang, B. (2004). Study on the interaction behaviour of geosynthetics and soil in China. GeoAsia 04 - Asian Regional Conference on Geosynthetics, Seoul, Korea: 104-115.

20. Dash, S. K. (2010). Influence of relative density of soil on performance of geocell-reinforced sand foundations. Journal of Materials in Civil Engineering, 22(5), 533-538.

21. Ferreira, F. B., Vieira, C. S. \& Lopes, M. (2015). Direct shear behaviour of residual soil-geosynthetic interfaces-influence of soil moisture content, soil density and geosynthetic type. Geosynthetics International, 22(3), 257-272.

22. Ferreira, F. B., Vieira, C. S., Lopes, M. L. \& Carlos, D. M. (2016). Experimental investigation on the pull out behaviour of geosynthetics embedded in a granite residual soil. European Journal of Environmental and Civil Engineering, 20(9), 1147-1180.

23. Goodhue, M.J., Edil, T.B. and Benson, C.H. (2001). Interaction offoundary sands with geosynthetics. Journal of Geotechnical and Geoenvironmental Engineering, april, 353-362.

24. Horpibulsuk, S., \& Niramitkornburee, A. (2010). Pullout resistance of bearing reinforcement embedded in sand. Soils and Foundations, 50(2), 215-226.

25. Hsieh, C. W., Chen, G. H. \& Wu, J. H. (2011). The shear behaviour obtained from the direct shear and pull out tests for different poor graded soilgeosynthetic systems. Journal of Geo-Engineering, 6(1), 15-26.

26. Infante, D. J. U., Martinez, G. M. A., Arrua, P. A., \& Eberhardt, M. (2016). Shear Strength Behaviour of Different Geosynthetic Reinforced Soil Structure from Direct Shear Test. International Journal of Geosynthetics and Ground Engineering, 2(2), 17.

27. Jewell, R. A., Millilgan, G. W. E., Sarsby, R. W. \& Dubois, D. (1984). Interaction Between Soil and Geogrids. Proc. Sympon Polymer Grid Reinforcement in Civil Engineering, Science and Engineering Research Council and Netlon Limited.

28. Kargar, M. \& Mir Mohammad Hosseini, S. M. (2016). Influence of reinforcement stiffness and strength on load-settlement response of geocellreinforced sand bases. European Journal of Environmental and Civil Engineering, 1-18.

29. Kim, D. \& Ha, S. (2014). Effects of particle size on the shear behaviour of coarse grained soils reinforced with geogrid. Materials, 7(2), $963-979$.

30. Latha, M. G. \& Murthy, V. S. (2006). Investigations on sand reinforced with different geosynthetics. Geotechnical Testing Journal, $29(6), 474-481$.

31. Lee, K. M. \& Manjunath, V. R. (2000). Soil-geotextile interface friction by direct shear tests. Canadian geotechnical journal, 37(1), 238-252.

32. Liu, C. N., Zornberg, J. G., Chen, T. C., Ho, Y. H. \& Lin, B. H. (2009). Behavior of geogrid-sand interface in direct shear mode. Journal of geotechnical and geoenvironmental engineering, 135(12), 1863-1871. 
33. Liu, C. N., Yang, K. H. \& Nguyen, M. D. (2014). Behavior of geogrid-reinforced sand and effect of reinforcement anchorage in large-scale plane strain compression. Geotextiles and Geomembranes, 42(5), 479-493.

34. Lopes, M. L. \& Ladeira, M. (1996). Influence of the confinement, soil density and displacement rate on soil-geogrid interaction. Geotextiles and Geomembranes, 14(10), 543-554.

35. Lopes, M. L. \& Silvano, R. (2010). Soil/geotextile interface behaviour in direct shear and pullout movements. Geotechnical and geological engineering, 28(6), 791-804.

36. Lopez, M.L. (2002). Soil - Geosynthetic interaction. Geosynthetics and their application, Thomas Telford, London.

37. Makkar, F. M., Chandrakaran, S., \& Sankar, N. (2019). Experimental Investigation of Response of Different Granular Soil-3D Geogrid Interfaces Using Large-Scale Direct Shear Tests. Journal of Materials in Civil Engineering, 31(4), 04019012. https://doi.org/10.1061/(ASCE)MT.1943-5533.0002645

38. Moghaddas Tafreshi, S. N., Joz Darabi, N., Tavakoli Mehrjardi, G. \& Dawson, A. (2016). Experimental and numerical investigation of footing behaviour on multi-layered rubber-reinforced soil. European Journal of Environmental and Civil Engineering, 1-24.

39. Mosallanezhad, M., Sadat Taghavi, S. H., \& Khadiv Sarvestani, M. (2016). Large-scale pullout testing of a new 'rooted'geogrid. International Journal of Physical Modelling in Geotechnics, 17(3), 195-203. https://doi.org/10.1680/jphmg.15.00029

40. Mosallanezhad, M., Sadat Taghavi, S. H. \& Khadiv Sarvestani, M. (2017). Large-scale pullout testing of a new 'rooted'geogrid. International Journal of Physical Modelling in Geotechnics, 17(3), 195-203.

41. Palmeira, E. M. (2004). Bearing Force Mobilization in Pull-Out Tests on Geogrids. Geotextiles and Geomembranes 22(6):481509. DOI:10.1016/j.geotexmem.2004.03.007

42. Palmeira, E. M. (2009). Soil-geosynthetic interaction: Modelling and analysis. Geotextiles and Geomembranes, 27(5), 368-390.

43. Prashanth, V., Krishna, A. M. \& Dash, S. K. (2016). Pull out Tests Using Modified Direct Shear Test Setup for Measuring Soil-Geosynthetic Interaction Parameters. International Journal of Geosynthetics and Ground Engineering, 2(2), 10.

44. Sadat Taghavi, S. H. \& Mosallanezhad, M. (2016). Experimental analysis of large-scale pullout tests conducted on polyester anchored geogrid reinforcement systems. Canadian Geotechnical Journal, 54(5), 621-630.

45. Tatlisoz, N., Edil, T. B. \& Benson, C. H. (1998). Interaction between reinforcing geosynthetics and soil-tire chip mixtures. Journal of Geotechnical and Geoenvironmental Engineering, 124(11), 1109-1119.

46. Tavakoli Mehrjardi, G. \& Amjadi Sardehaei, E. (2017). Design graphs to estimate reduction factor of nonwoven geotextiles due to installation process. European Journal of Environmental and Civil Engineering, 1-14.

47. Thuo, J. N., Yang, K. H. \& Huang, C. C. (2015). Infiltration into unsaturated reinforced slopes with nonwoven geotextile drains sandwiched in sand layers. Geosynthetics International, 22(6), 457-474.

48. Tuna, S. C., \& Altun, S. (2012). Mechanical behaviour of sand-geotextile interface. Scientia Iranica, 19(4), 1044-1051.

49. Varuso, R. J., Grieshaber, J. B. \& Nataraj, M. S. (2005). Geosynthetic reinforced levee test section on soft normally consolidated clays. Geotextiles and Geomembranes, 23(4), 362-383.

50. Wang, J., Liu, F. Y., Wang, P. \& Cai, Y. Q. (2016). Particle size effects on coarse soil-geogrid interface response in cyclic and post-cyclic direct shear tests Geotextiles and Geomembranes, 44(6), 854-861.

51. Xu, Y., Williams, D. J., \& Serati, M. (2018a). Investigation of shear strength of interface between road base and geosynthetics using large-scale singlestage and multi-stage direct shear test. Road Materials and Pavement Design, 1-24. https://doi.org/10.1080/14680629.2018.1561378

52. Xu, C., Liang, C., Shen, P. and Chai F. (2020). Experimental and numerical studies on the reinforcing mechanisms of geosynthetic - reinforcedgranular soil under a plane strain condition. Soils and Foundations, Vol. 60, Issue 2, 466-477.

53. Wang, J.Q., Xu, L.J. and Lin, Z.N. (2020). Study on creep characteristics of geogrids considered sand - geosynthetics interaction under different

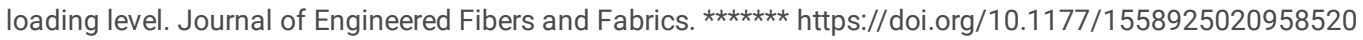

54. Xu, P., Hatami, K. and Jiang, G. ( $\left.{ }^{(* \star *}\right)$. Centrifuge study of reinforced soil walls with different backfill compaction densities. Geosynthetics

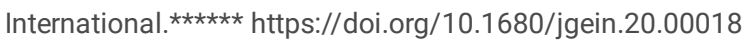

\section{Tables}

Due to technical limitations, table 1 is only available as a download in the Supplemental Files section.

Table 2. Sand characteristics. 


\begin{tabular}{|c|c|c|c|}
\hline \multirow{2}{*}{ Description } & \multirow{2}{*}{ ASTM } & \multicolumn{2}{|c|}{ Sands } \\
\hline & & $s_{c}$ & $S_{f}$ \\
\hline $\mathrm{D}_{10}(\mathrm{~mm})$ & D422-07 & 0.15 & 0.14 \\
\hline $\mathrm{D}_{30}(\mathrm{~mm})$ & & 0.60 & 0.18 \\
\hline $\mathrm{D}_{50}(\mathrm{~mm})$ & & 1.00 & 0.22 \\
\hline $\mathrm{D}_{\mathrm{g}}(\mathrm{mm})$ & & 1.68 & 0.24 \\
\hline & & 11.2 & 1.71 \\
\hline $\mathrm{C}_{\mathrm{u}}$ & & 1.43 & 0.96 \\
\hline $\mathrm{C}_{\mathrm{c}}$ & D4253-16 & 17.50 & 15.50 \\
\hline $\mathrm{Y}_{\mathrm{dmax}}\left(\mathrm{kN} / \mathrm{m}^{3}\right)$ & D4254-16 & 16.00 & 13.80 \\
\hline$Y_{d \min }\left(k N / m^{3}\right)$ & D3080-11 & 44.8 & 33.8 \\
\hline$\Phi\left({ }^{\circ}\right)$ & D2487-17 & sw & SP \\
\hline uscs & & & \\
\hline
\end{tabular}

Table 3. Geogrid CE131 characteristics (www.meshiran.com)

\begin{tabular}{|ll|}
\hline Description & Value \\
\hline Polymer & HDPE \\
Form & Sheet \\
Color & Black \\
Aperture size $(\mathrm{mm} \times \mathrm{mm})$ & $27 \times 27$ \\
Mesh Thickness $(\mathrm{mm})$ & 5.2 \\
Mass per unit area $\left(\mathrm{g} / \mathrm{m}^{2}\right)$ & 660 \\
Tensile strength $(\mathrm{kN} / \mathrm{m})$ & 5.8 \\
Elongation at maximum load $(\%)$ & 16.5 \\
Load at $10 \%$ extension $(\mathrm{kN} / \mathrm{m})$ & 5.2 \\
Elongation at $1 / 2$ peak strength $(\%)$ & 3.7 \\
Elastic normal stiffness of geogrid $(\mathrm{kN} / \mathrm{m})$ & 28 \\
Axial stiffness $(\mathrm{kN} / \mathrm{m})$ & 11.7 \\
\hline
\end{tabular}

Table 4. Anchor specifications.

\begin{tabular}{|lll|}
\hline Anchor & Surface Area $\left(\mathrm{cm}^{2}\right)$ & Base Area $\left(\mathrm{cm}^{2}\right)$ \\
\hline $\mathrm{A}_{1}$ & 9.42 & 1.77 \\
$\mathrm{~A}_{2}$ & 3.34 & 0.57 \\
$\mathrm{~A}_{3}$ & 2.27 & 0.57 \\
\hline
\end{tabular}

Table 5: Summary of direct shear tests results. 


\begin{tabular}{|c|c|c|c|c|c|c|c|c|c|c|c|c|}
\hline \multirow[t]{2}{*}{ Sample } & \multicolumn{3}{|c|}{$\sigma_{\mathrm{n}}=12.5(\mathrm{kPa})$} & \multicolumn{3}{|c|}{$\sigma_{\mathrm{n}}=25(\mathrm{kPa})$} & \multicolumn{3}{|l|}{$\sigma_{\mathrm{n}}=50(\mathrm{kPa})$} & \multirow[t]{2}{*}{$\Phi$} & \multirow[t]{2}{*}{$\delta_{a}$} & \multirow[t]{2}{*}{$\delta_{e}$} \\
\hline & $\tau_{\max }(\mathrm{kPa})$ & $C_{i}$ & $C_{i e}$ & $\tau_{\max }(\mathrm{kPa})$ & $c_{i}$ & $C_{i e}$ & $\tau_{\max }(\mathrm{kPa})$ & $C_{i}$ & $\mathrm{C}_{\mathrm{ie}}$ & & & \\
\hline $\mathrm{S}_{\mathrm{c}}$ & 13.89 & 1.00 & - & 22.60 & 1.00 & - & 50.40 & 1.00 & - & $44.8^{\circ}$ & - & - \\
\hline$S_{c} G$ & 14.32 & 1.03 & 1.00 & 22.67 & 1.00 & 1.00 & 44.51 & 0.88 & 1.00 & - & $39.2^{\circ}$ & - \\
\hline $\mathrm{S}_{c} \mathrm{~A}_{1} \mathrm{~L}_{1}$ & 19.05 & 1.37 & 1.33 & 30.59 & 1.35 & 1.35 & 63.23 & 1.26 & 1.42 & - & - & $50.1^{\circ}$ \\
\hline $\mathrm{S}_{c} \mathrm{~A}_{2} \mathrm{~L}_{1}$ & 17.64 & 1.27 & 1.23 & 28.27 & 1.25 & 1.25 & 58.69 & 1.17 & 1.32 & - & - & $48.1^{\circ}$ \\
\hline $\mathrm{S}_{\mathrm{c}} \mathrm{A}_{3} \mathrm{~L}_{1}$ & 16.18 & 1.17 & 1.13 & 25.99 & 1.15 & 1.15 & 53.80 & 1.07 & 1.21 & - & - & $45.5^{\circ}$ \\
\hline$S_{c} A_{1} L_{2}$ & 16.65 & 1.20 & 1.16 & 26.83 & 1.19 & 1.18 & 57.43 & 1.14 & 1.29 & - & - & $47.9^{\circ}$ \\
\hline $\mathrm{S}_{c} \mathrm{~A}_{2} \mathrm{~L}_{2}$ & 16.36 & 1.18 & 1.14 & 26.36 & 1.17 & 1.16 & 53.56 & 1.06 & 1.20 & - & - & $45.1^{\circ}$ \\
\hline $\mathrm{S}_{c} \mathrm{~A}_{3} \mathrm{~L}_{2}$ & 15.35 & 1.10 & 1.07 & 24.91 & 1.10 & 1.09 & 51.18 & 1.01 & 1.15 & - & - & $44.1^{\circ}$ \\
\hline $\mathrm{S}_{c} \mathrm{~A}_{1} \mathrm{~L}_{3}$ & 16.04 & 1.16 & 1.12 & 25.33 & 1.12 & 1.15 & 55.96 & 1.11 & 1.26 & - & - & $47.4^{\circ}$ \\
\hline $\mathrm{S}_{c} \mathrm{~A}_{2} \mathrm{~L}_{3}$ & 15.94 & 1.15 & 1.11 & 25.46 & 1.13 & 1.12 & 51.56 & 1.02 & 1.16 & - & - & $43.9^{\circ}$ \\
\hline $\mathrm{S}_{\mathrm{c}} \mathrm{A}_{3} \mathrm{~L}_{3}$ & 14.91 & 1.07 & 1.04 & 24.11 & 1.06 & 1.06 & 50.29 & 0.99 & 1.13 & - & - & $43.7^{\circ}$ \\
\hline$S_{f}$ & 9.49 & 1.00 & - & 18.29 & 1.00 & - & 34.71 & 1.00 & - & $33.8^{\circ}$ & - & - \\
\hline$S_{f} G$ & 9.87 & 1.04 & 1.00 & 17.94 & 0.98 & 1.00 & 30.35 & 0.87 & 1.00 & - & $28.3^{\circ}$ & - \\
\hline $\mathrm{S}_{f} \mathrm{~A}_{1} \mathrm{~L}_{1}$ & 11.57 & 1.22 & 1.17 & 21.75 & 1.19 & 1.21 & 40.93 & 1.18 & 1.35 & - & - & $38.0^{\circ}$ \\
\hline $\mathrm{S}_{\mathrm{f}} \mathrm{A}_{2} \mathrm{~L}_{1}$ & 10.70 & 1.13 & 1.08 & 20.28 & 1.11 & 1.13 & 37.64 & 1.08 & 1.24 & - & - & $35.6^{\circ}$ \\
\hline $\mathrm{S}_{f} \mathrm{~A}_{3} \mathrm{~L}_{1}$ & 10.21 & 1.08 & 1.03 & 19.20 & 1.05 & 1.07 & 35.94 & 1.04 & 1.18 & - & - & $34.4^{\circ}$ \\
\hline $\mathrm{S}_{\mathrm{f}} \mathrm{A}_{1} \mathrm{~L}_{2}$ & 10.74 & 1.13 & 1.09 & 20.14 & 1.10 & 1.12 & 37.13 & 1.07 & 1.22 & - & - & $35.0^{\circ}$ \\
\hline $\mathrm{S}_{\mathrm{f}} \mathrm{A}_{2} \mathrm{~L}_{2}$ & 10.26 & 1.08 & 1.04 & 20.08 & 1.06 & 1.12 & 36.08 & 1.03 & 1.18 & - & - & $34.2^{\circ}$ \\
\hline $\mathrm{S}_{\mathrm{f}} \mathrm{A}_{3} \mathrm{~L}_{2}$ & 10.11 & 1.06 & 1.02 & 18.61 & 1.02 & 1.04 & 34.92 & 1.01 & 1.15 & - & - & $33.4^{\circ}$ \\
\hline$S_{f} A_{1} L_{3}$ & 10.47 & 1.10 & 1.06 & 19.67 & 1.07 & 1.10 & 35.89 & 1.03 & 1.18 & - & - & $33.9^{\circ}$ \\
\hline $\mathrm{S}_{\mathrm{f}} \mathrm{A}_{2} \mathrm{~L}_{3}$ & 10.06 & 1.06 & 1.02 & 18.60 & 1.02 & 1.04 & 34.29 & 0.99 & 1.13 & - & - & $32.7^{\circ}$ \\
\hline$S_{f} A_{3} L_{3}$ & 9.97 & 1.05 & 1.01 & 18.29 & 1.00 & 1.02 & 32.81 & 0.94 & 1.08 & - & - & $31.2^{\circ}$ \\
\hline
\end{tabular}

Note: $S_{c} A_{i} L j$ means "sand $S_{c}$, anchor $A_{i}$ with layout $L_{j}$.

\section{Figures}

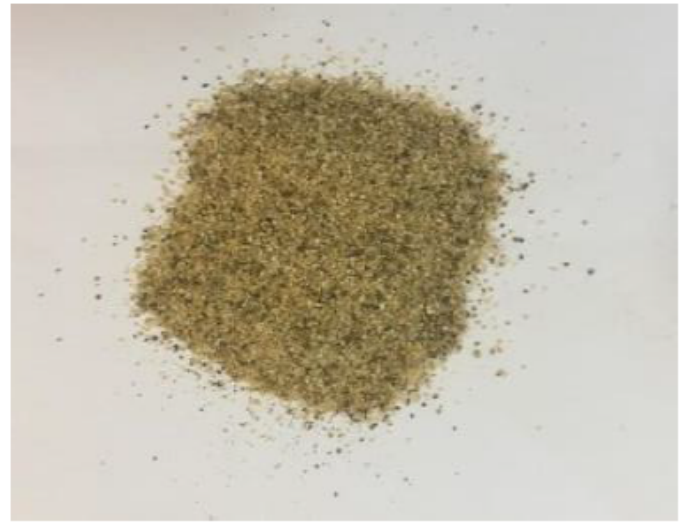

(a)

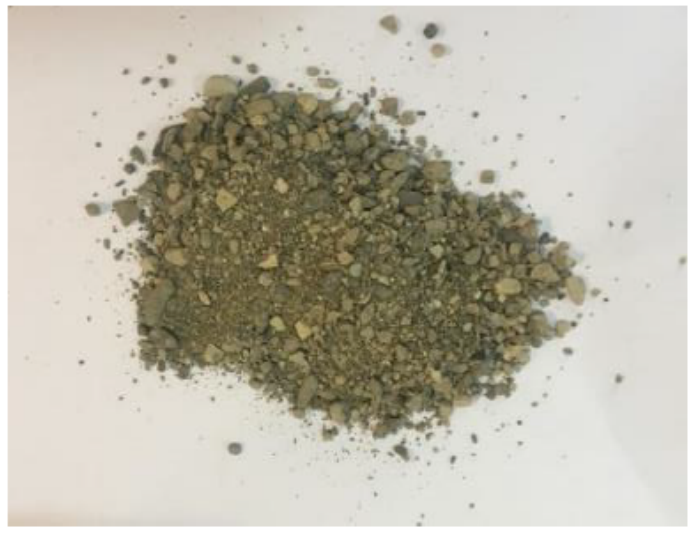

(b) 
Figure 1

Sands: a) Sf and b) Sc.

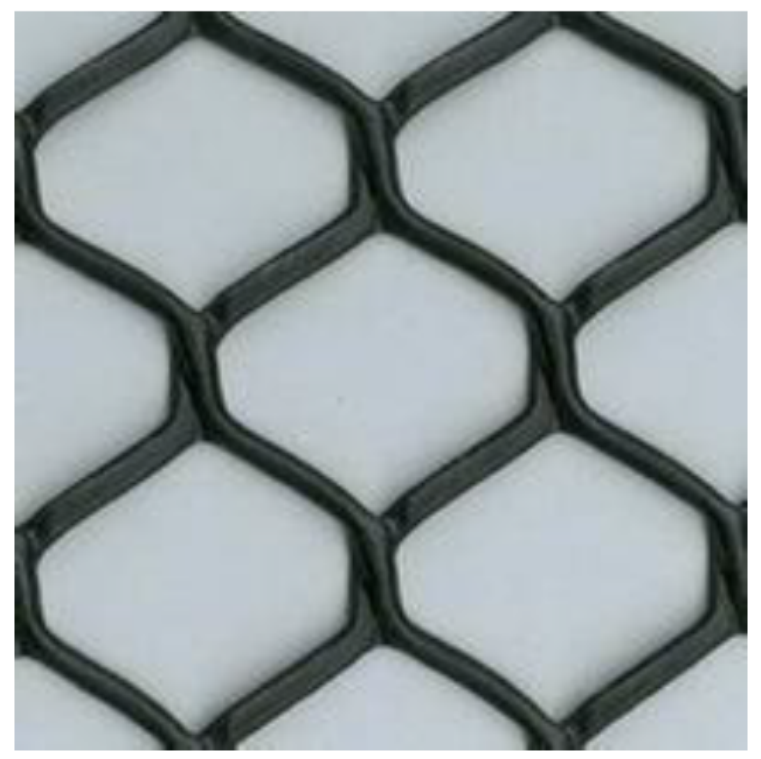

Figure 2

Geogrid CE131

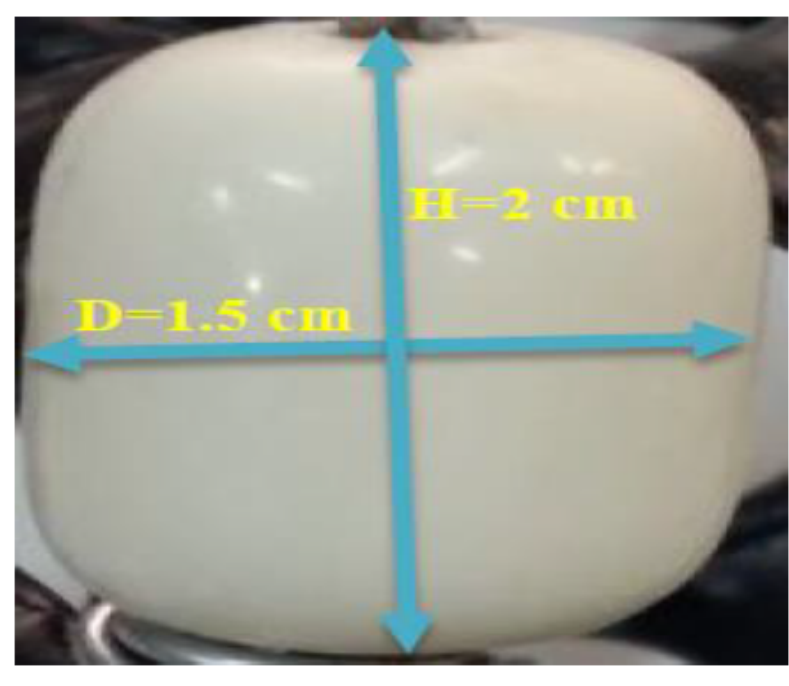

$\left(\mathrm{A}_{1}\right)$

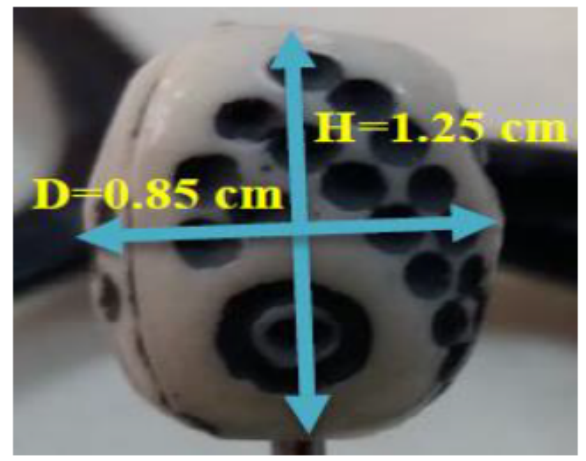

$\left(\mathrm{A}_{2}\right)$

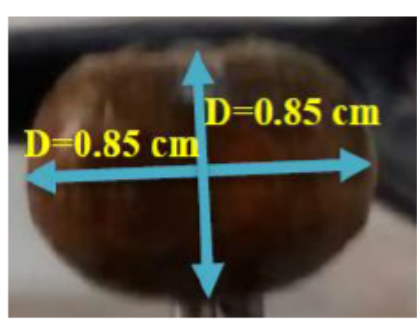

$\left(\mathrm{A}_{3}\right)$

\section{Figure 3}

Plastic elements (i.e. anchors) 


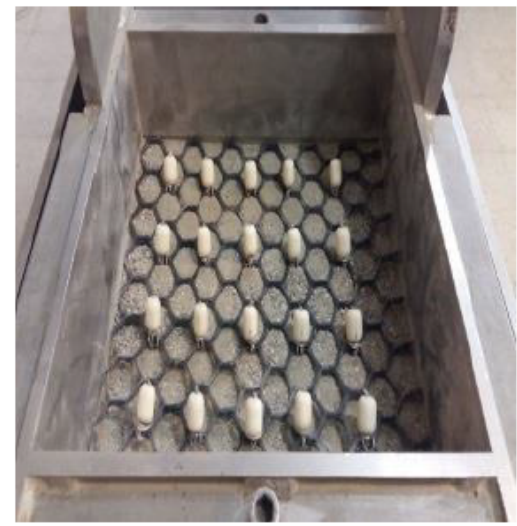

a) $\mathrm{L}_{1}=20$

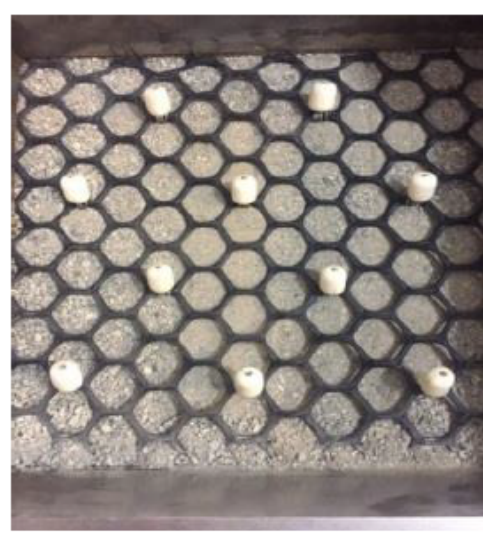

b) $\mathrm{L}_{2}=10$

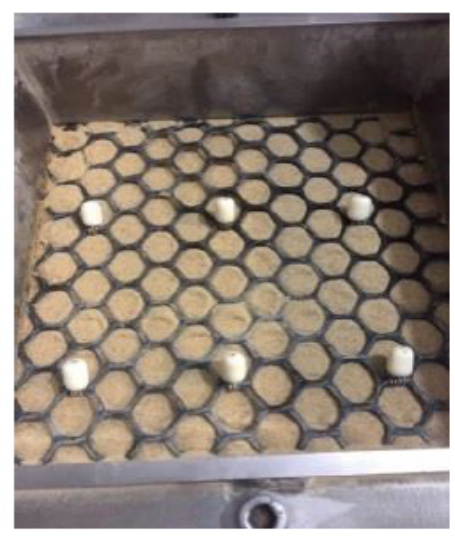

c) $\mathrm{L}_{3}=6$

Figure 4

Anchor arrangements

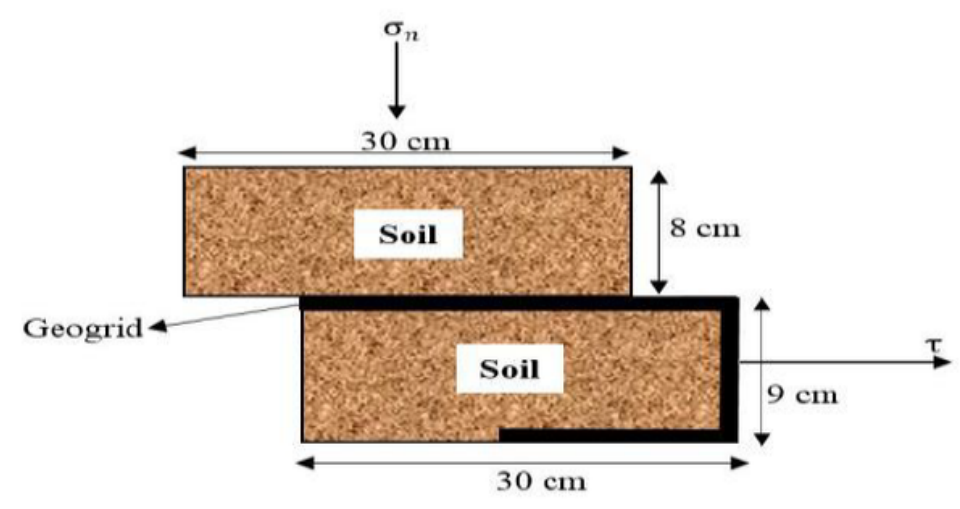

(a)

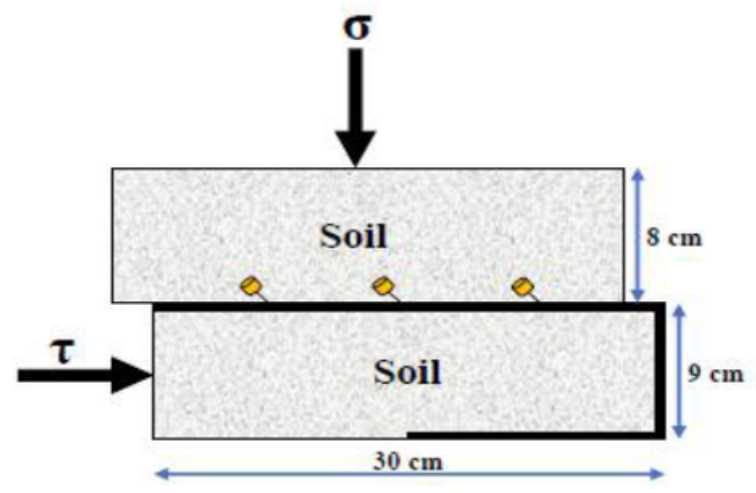

(b)

\section{Figure 5}

a) soil-geogrid ; b) soil-anchored geogrid 


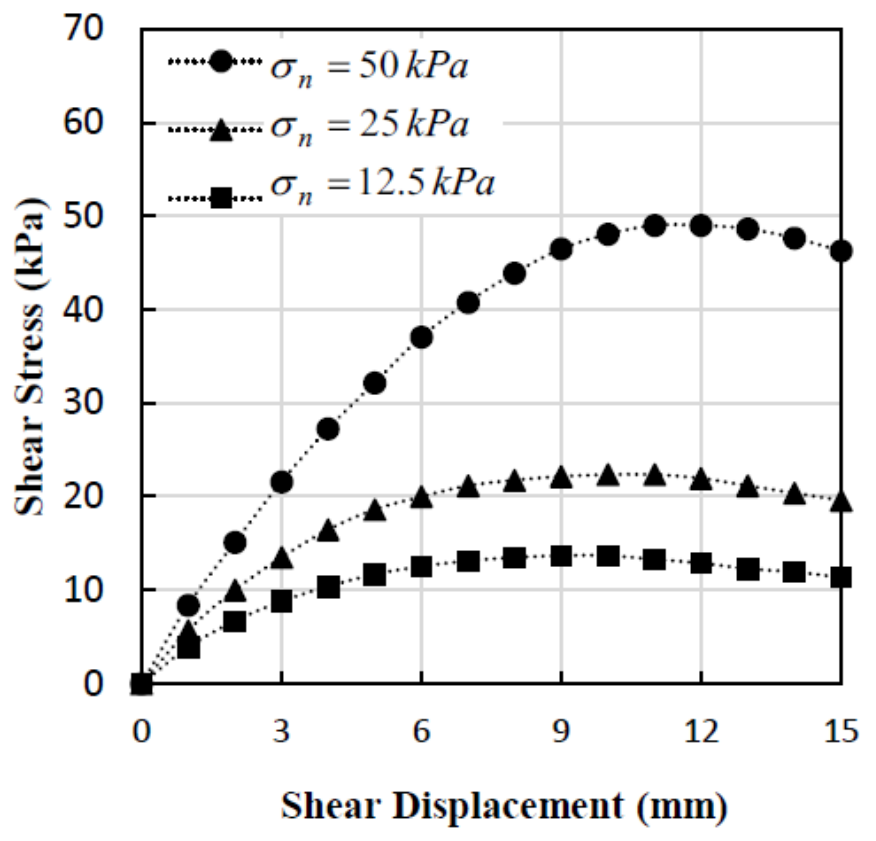

Figure 6

Shear stress-Shear displacement for Sc samples

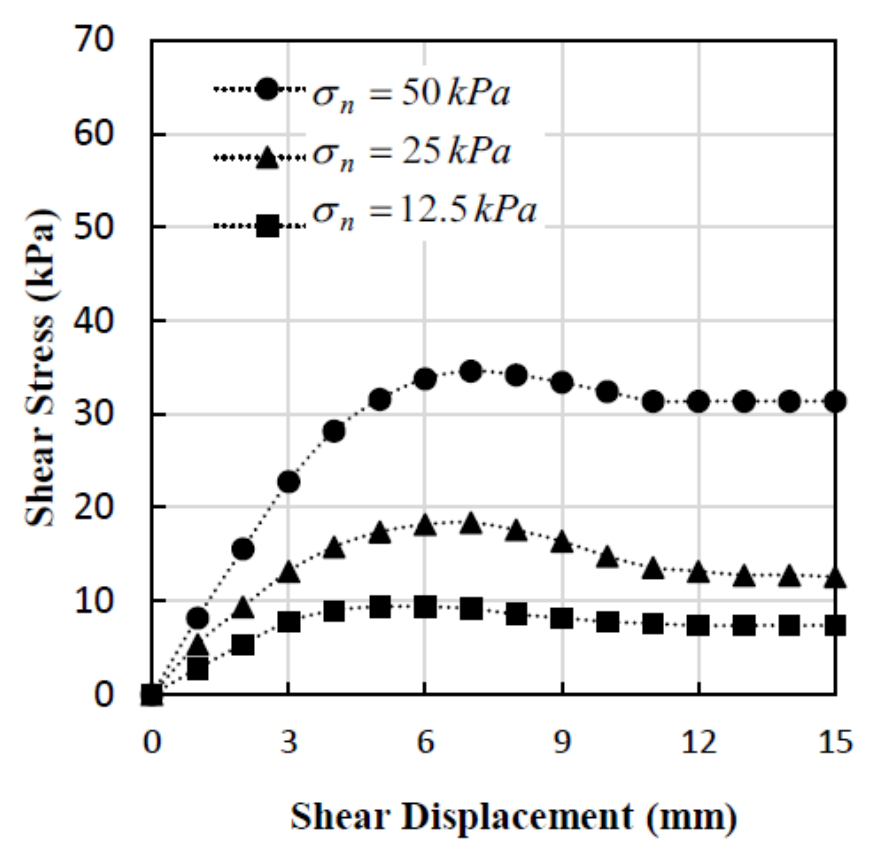

Figure 7

Shear stress-shear displacement for Sf samples 


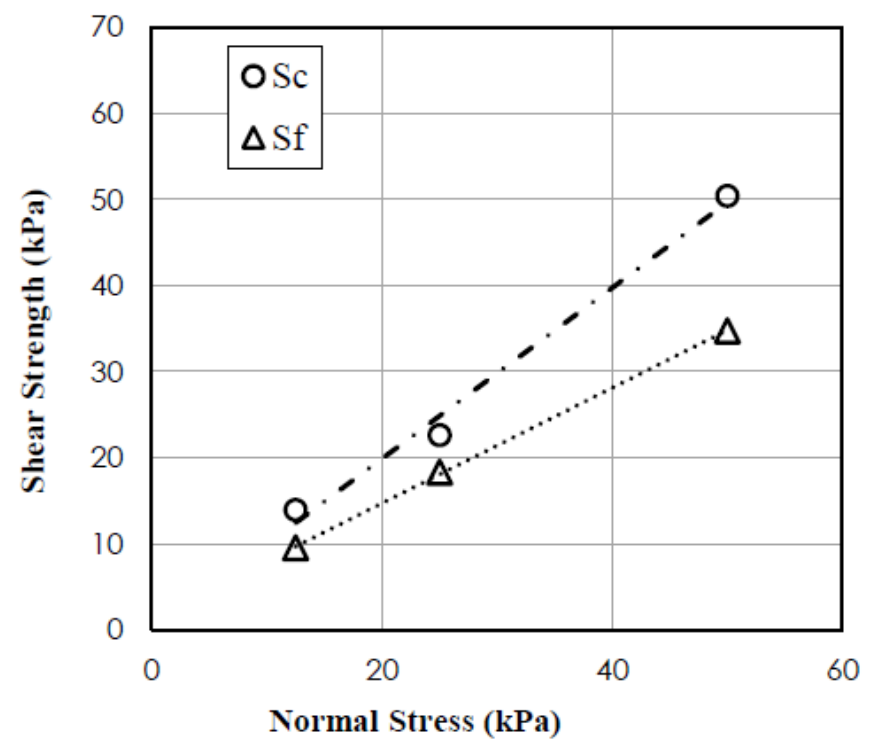

Figure 8

Failure envelopes for unreinforced Sc and Sf samples

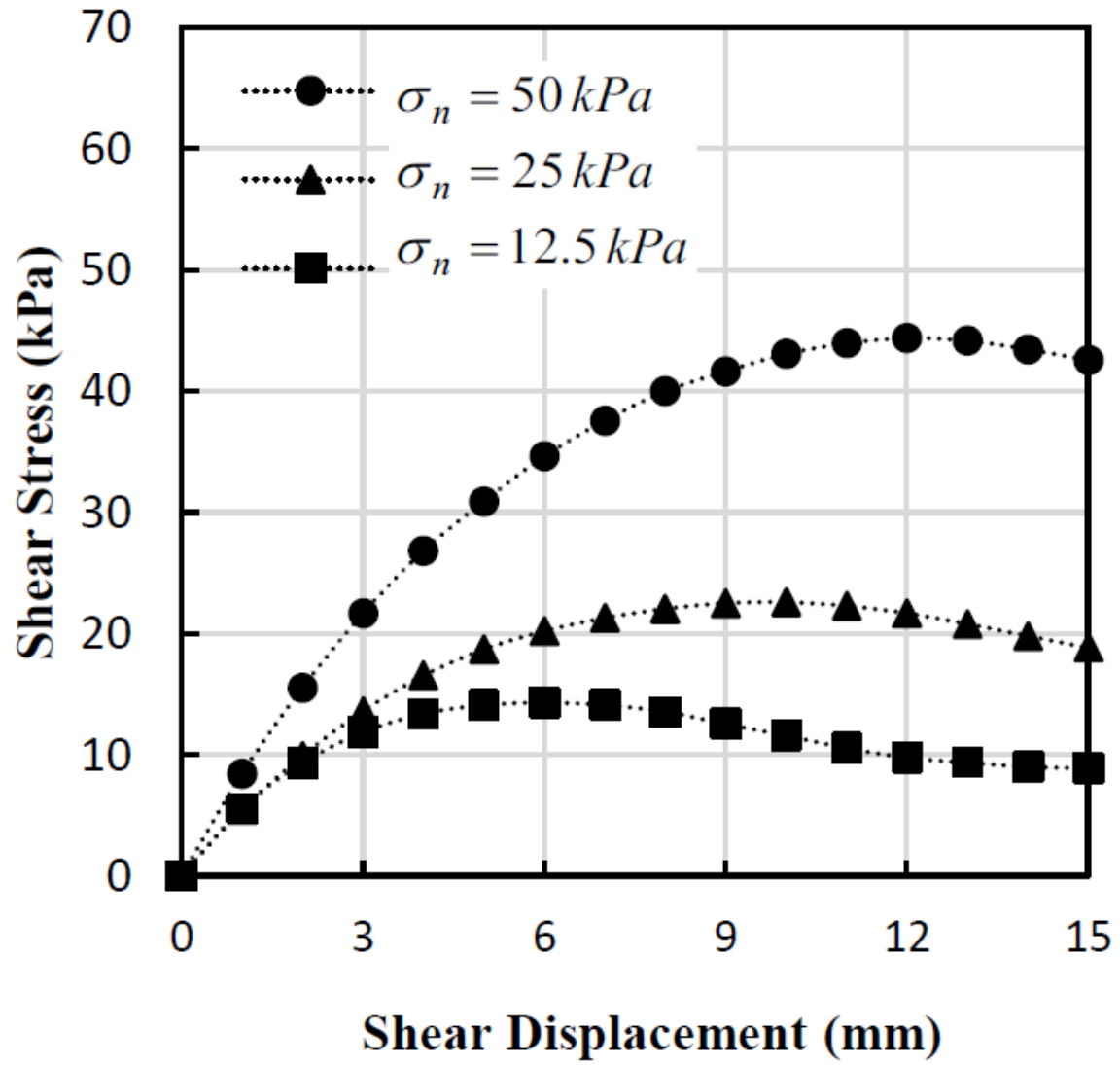

Figure 9

Shear stress-shear displacement for reinforced Sc samples 


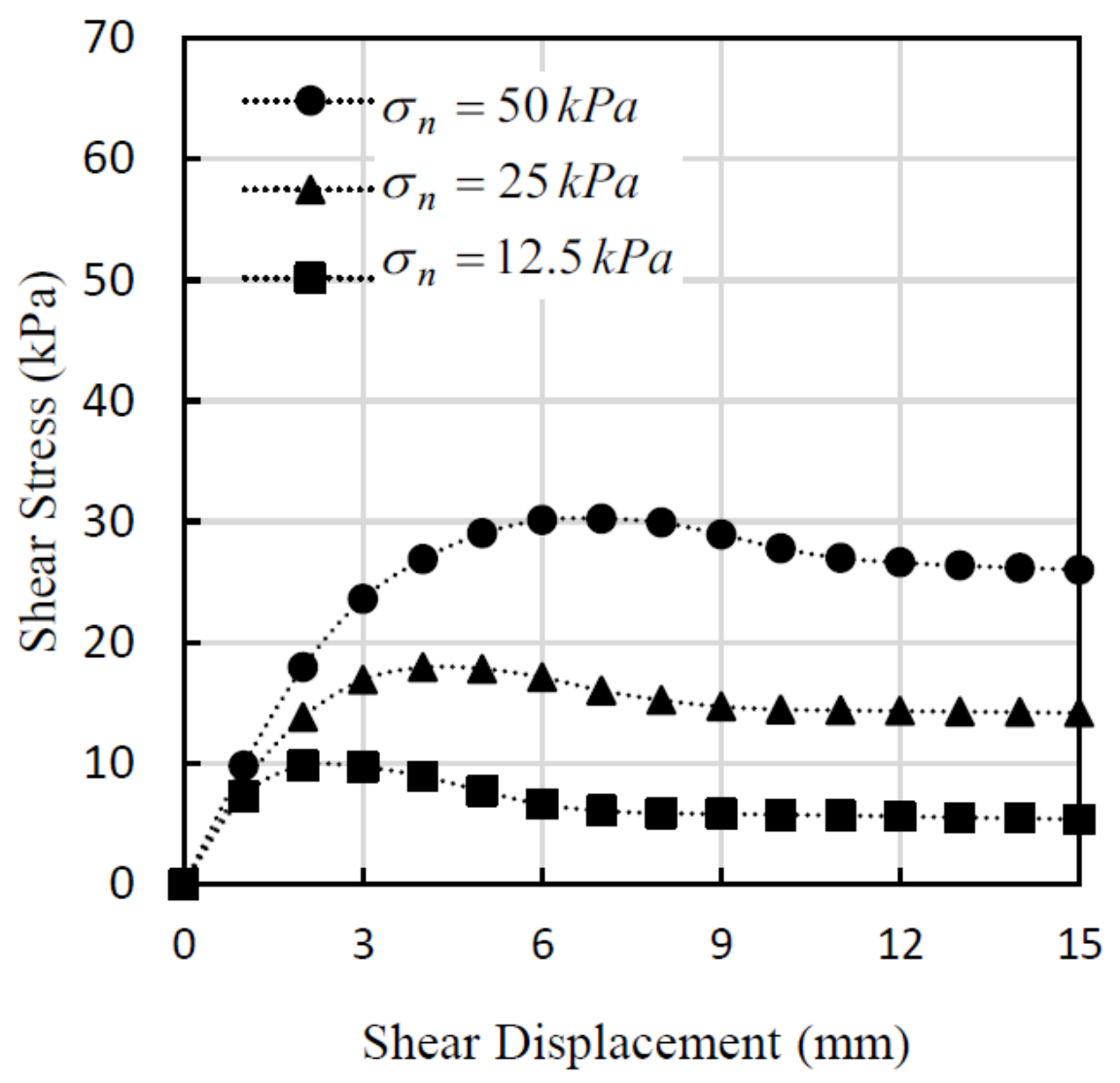

Figure 10

Shear stress - shear displacements for reinforced Sf samples

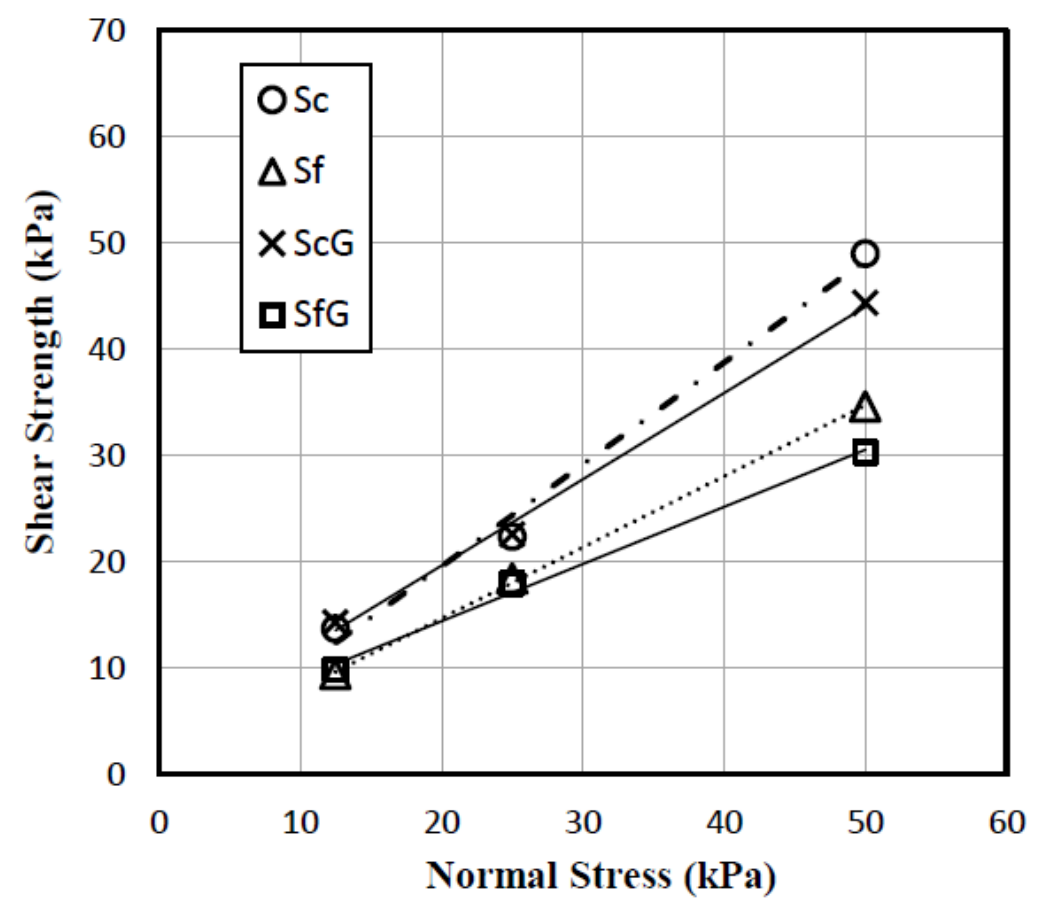

Figure 11

Failure envelopes for reinforced (ScG \& SfG) and unreinforced (Sc\&Sf) samples 


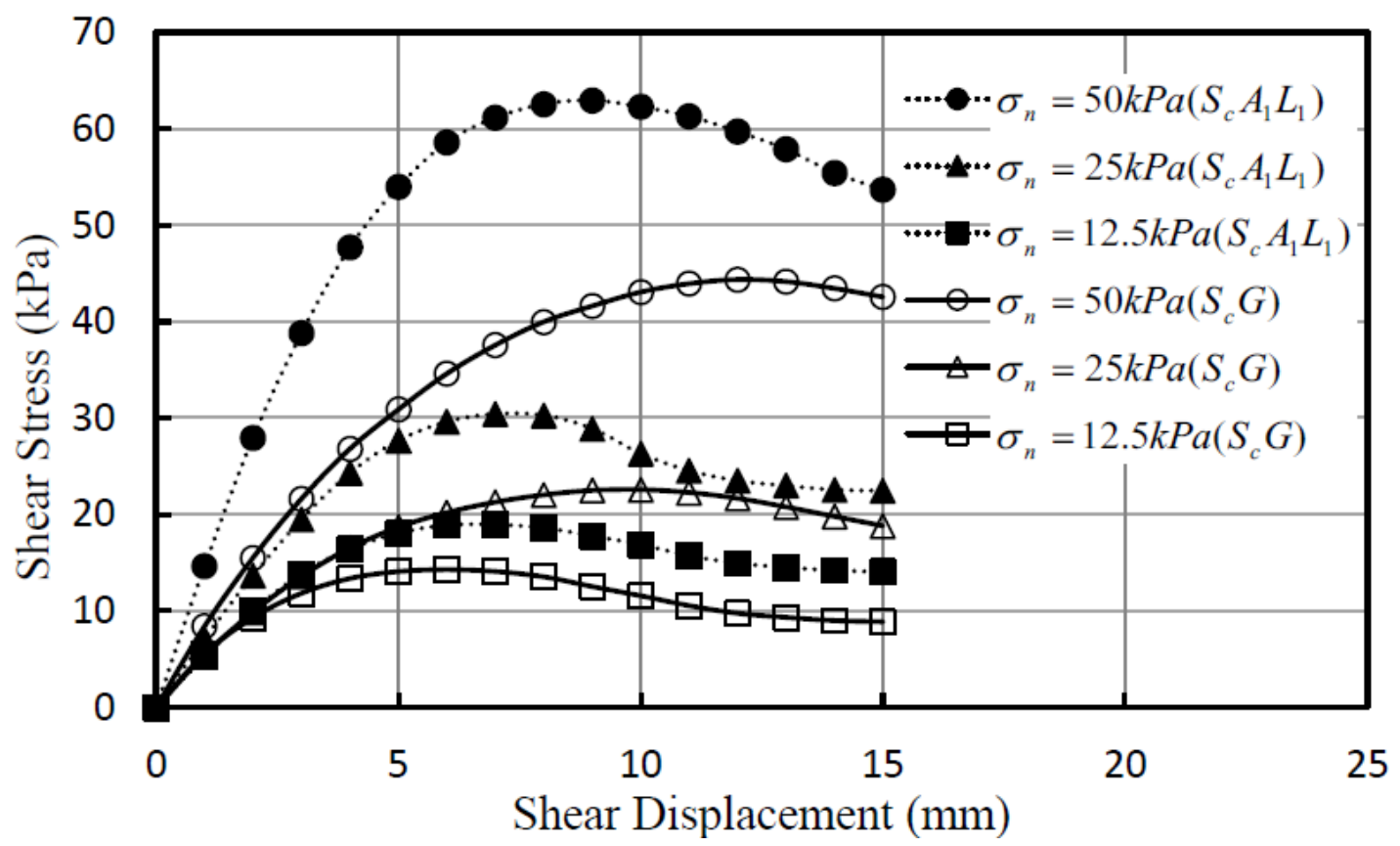

Figure 12

Shear stress - shear displacements for SCG and SCA1L1 samples

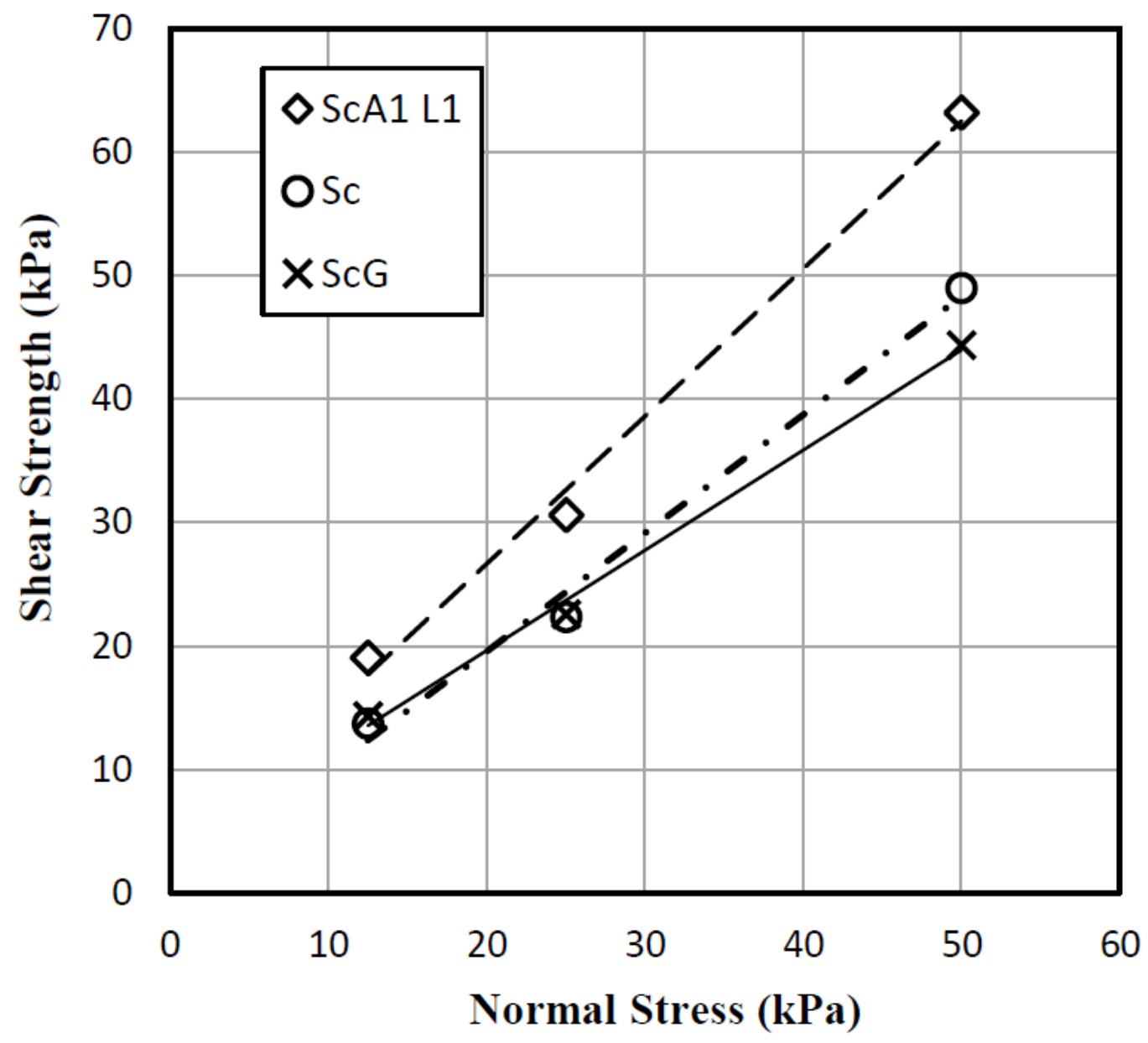

Figure 13

Failure envelopes for SC, SCG and SCA1L1 samples 


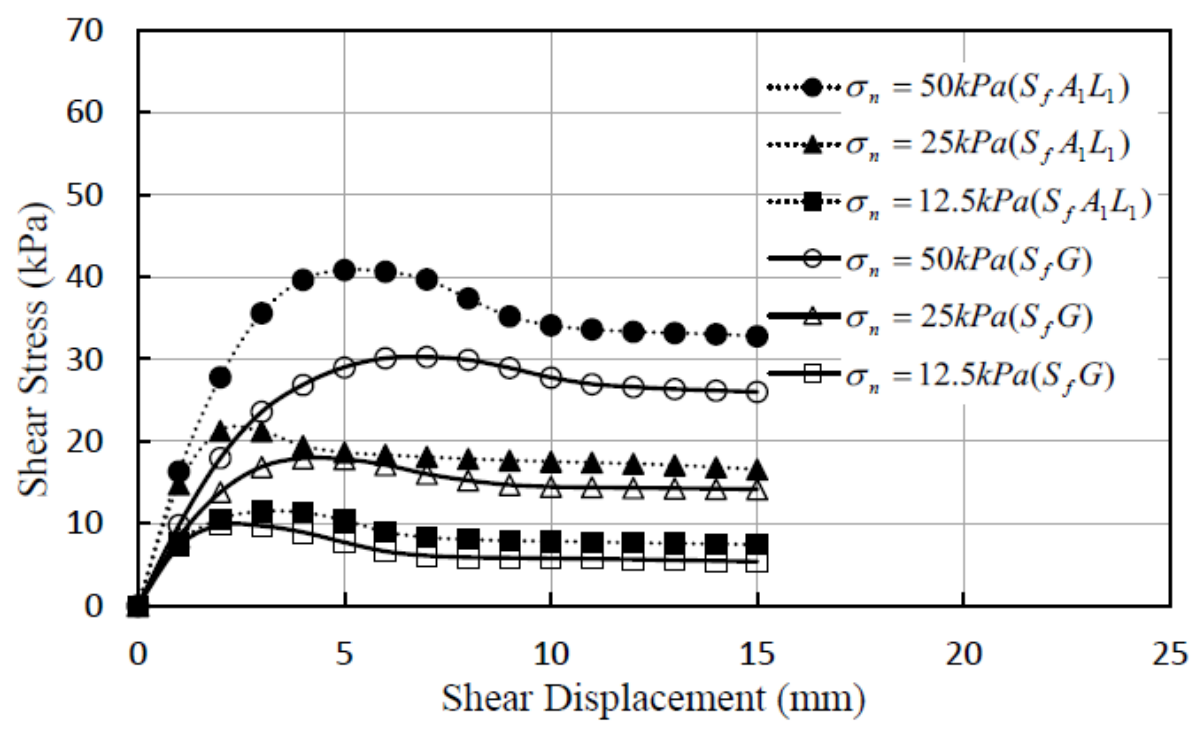

Figure 14

Shear stress - shear displacement for SfG and SfA1L1 samples

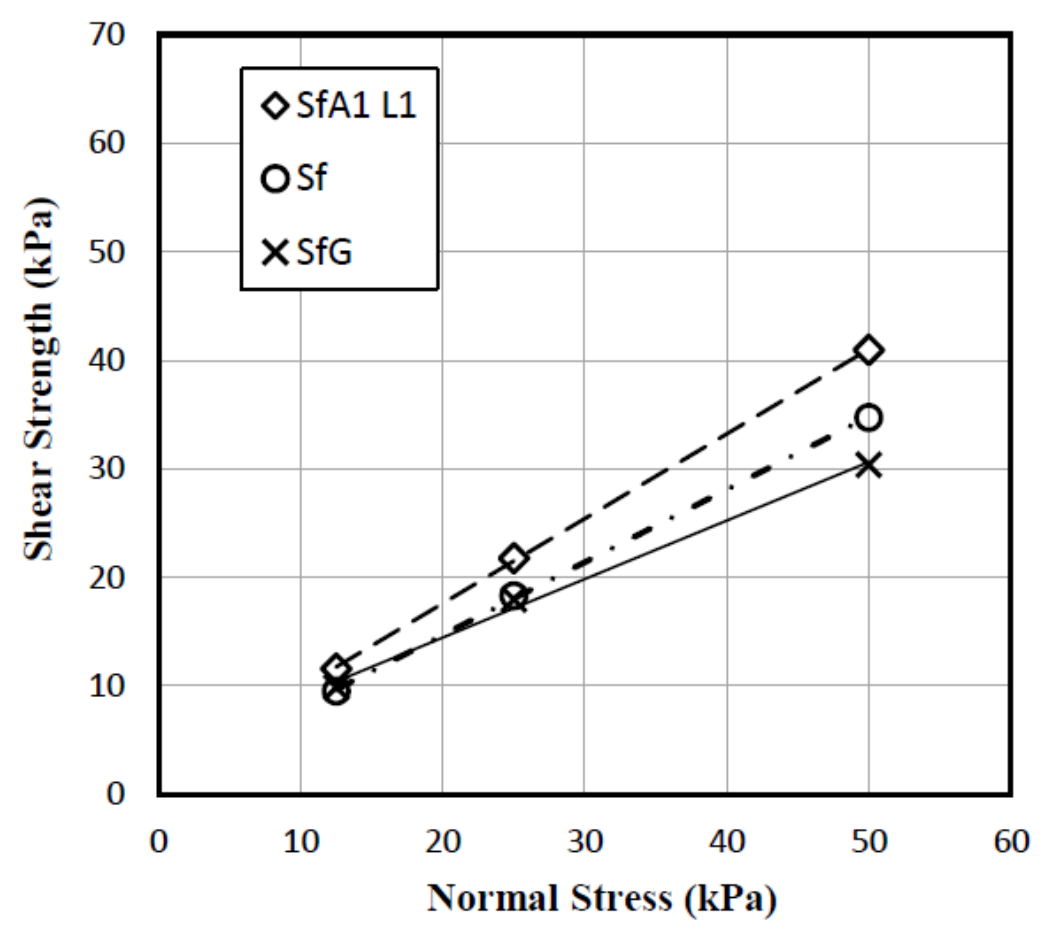

Figure 15

Failure envelopes for Sf , SfG and SfA1L1 samples 


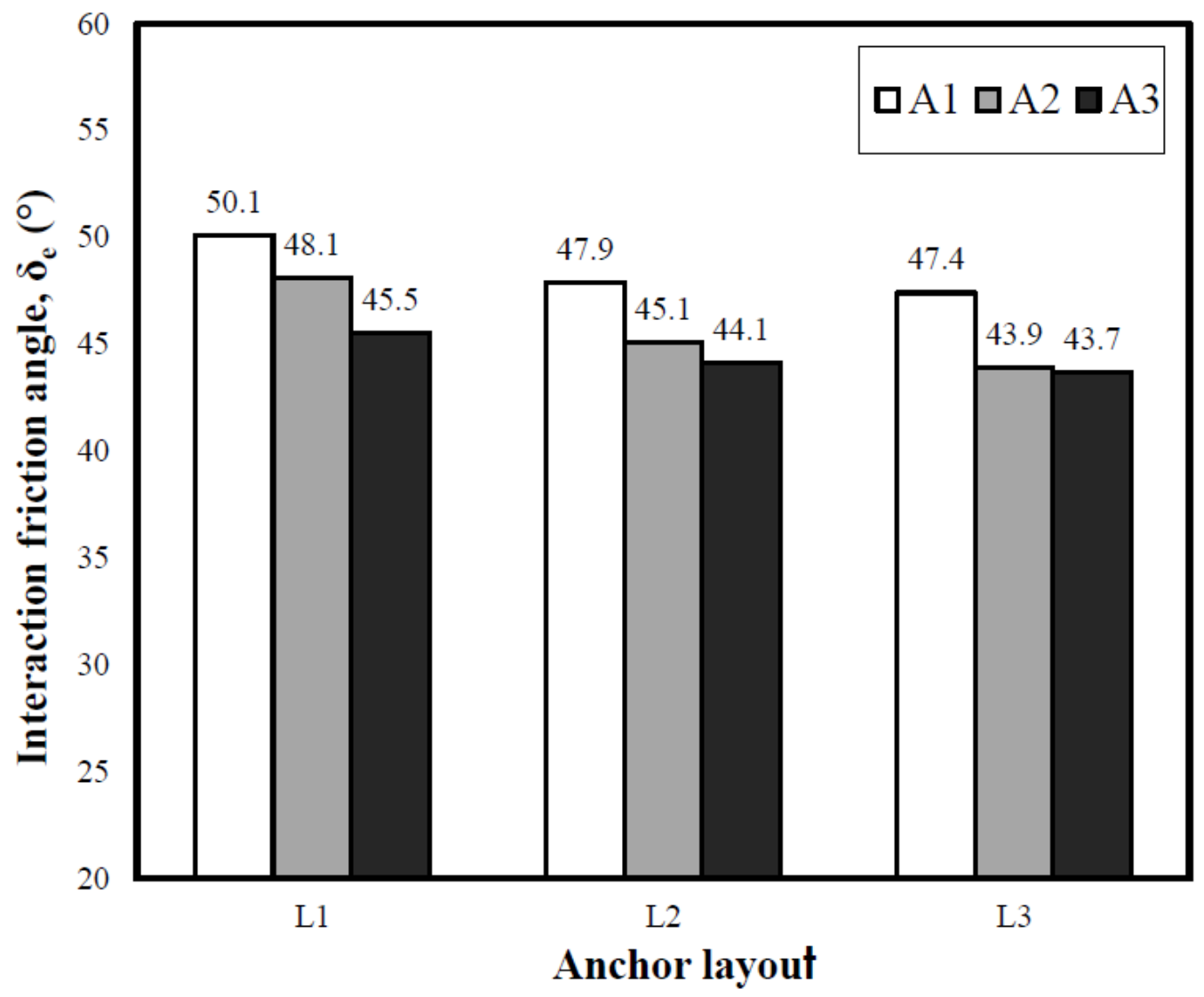

Figure 16

Variations of interaction friction angles versus anchor size and layouts

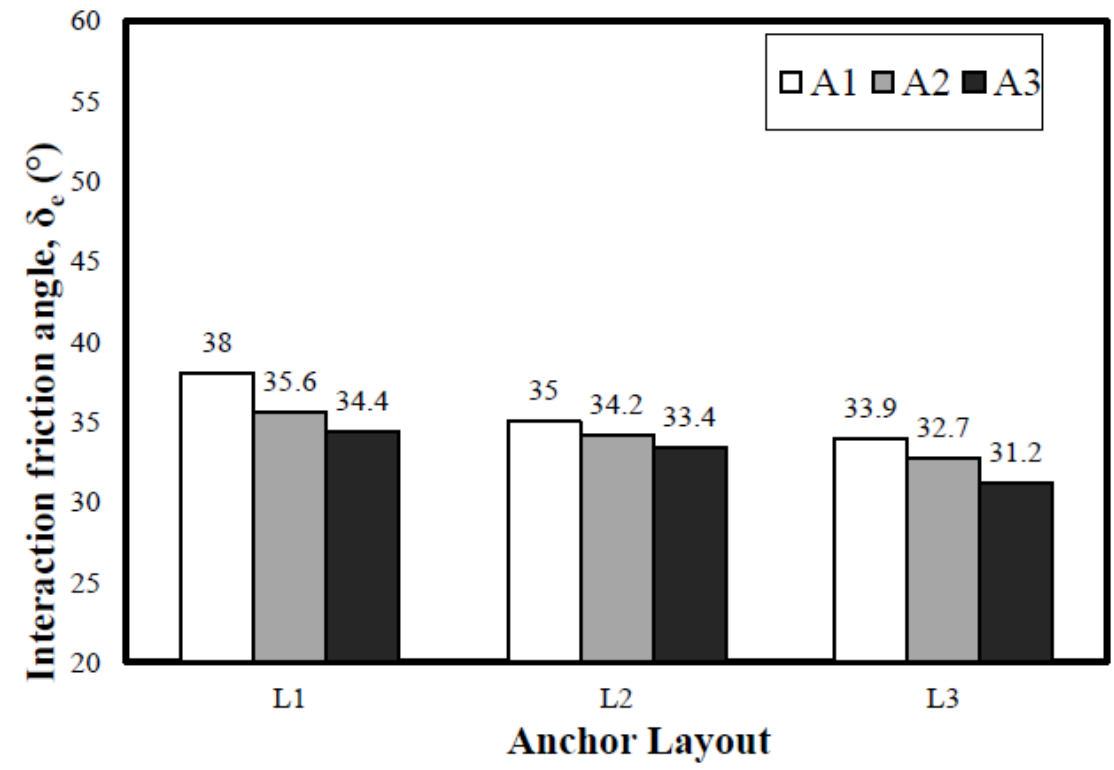

Figure 17

Variation of interaction friction angles versus anchor size and layouts

\section{Supplementary Files}

This is a list of supplementary files associated with this preprint. Click to download.

- Table1.docx 